\title{
Enflasyon ve Ekonomik Büyüme: Eşik Değer Analizi
}

Inflation and Economic Growth: Threshold Analysis

\section{Dr. Öğr. Üyesi Taner Sekmen ${ }^{1}$ - Dr. Öğr. Üyesi Seher Gülşah Topuz²}

Başvuru Tarihi: 09.08.2018

Kabul Tarihi: 10.04.2019

Öz

Bu çalışma enflasyon ve ekonomik büyüme ilişkisini OECD ülkeleri için sorgulamaktadır. Bu ilişkiyi ortaya çıkarabilmek için 1996-2016 yılları arası veriler panel eşik değer regresyon yöntemleri kullanılarak analiz edilmektedir. Çalışmanın bulguları enflasyon ve ekonomik büyüme arasındaki ilişkinin doğrusal olmadığ yönündedir. Enflasyon eşik değeri OECD ülkeleri için \%3,6207 olarak tespit edilmektedir. Enflasyon oranı bu değerin altında iken enflasyonun ekonomik büyüme üzerindeki etkisi pozitif fakat istatistiksel olarak anlamsizken enflasyon oranı bu değerin üzerine çıktığında büyüme üzerinde bozucu etkiler yaratmaktadır. $\mathrm{Bu}$ bulgularm özellikle enflasyon hedeflemesi rejimi uygulayan ülkeler başta olmak üzere para politikasının yürütülmesinde politika yapıcılara yardımcı olması beklenmektedir.

Anahtar Kelimeler: Enflasyon, Ekonomik Büyüme, Doğrusal Olmayan Etkiler, Eşik Değer Analizi

\section{Abstract}

This study investigates the relationship between inflation and economic growth for OECD countries. In order to clarify this relationship, panel data from 1996 to 2016 are analyzed using panel threshold regression methods. Findings of the study suggest that the relationship between inflation and economic growth is not linear. The inflation threshold level is estimated at $3,6207 \%$ for OECD countries. When the inflation rate is lower than this threshold value, the effect of inflation on economic growth is positive but statistically insignificant. When the inflation rate rises above this threshold value, inflation has disruptive effects on growth. These findings are expected to help policymakers in the implementation of the monetary policy, particularly in the countries that implement the inflation targeting regime.

Keywords: Inflation, Economic Growth, Non-Linear Effects, Threshold Analysis

\footnotetext{
${ }^{1}$ Eskişehir Osmangazi Üniversitesi İIBF, tsekmen@ogu.edu.tr, ORCID: 0000-0002-0363-3765
}

${ }^{2}$ Eskişehir Osmangazi Üniversitesi İİB, stopuz@ogu.edu.tr, ORCID: 0000-0002-7761-6255 


\section{Giriş}

Enflasyon ve ekonomik büyüme ilişkisi 1960'lardan itibaren makroekonomik teori tartışmalarının merkezinde yer almakta ve bu tartışma farklı sonuçları ortaya çıkarmaktadır. Monetarist karşı devrimine kadar Keynesyen anlayışa ait Phillips eğrisi modelleri enflasyon ve ekonomik büyüme arasında pozitif bir ilişki kurmaktaydı. Stagflasyon olgusunu açıklamakta başarısız olan Keynesyen Phillips eğrisi, Monetarist ve Yeni Klasik iktisatçıların doğal işsizlik oranı ve dikey Phillips eğrisi gibi yeni kavramları ortaya çıkarmasına yol açmıştır. Bu kavramlar enflasyon oranındaki artışların ekonomik büyüme ve işsizlik üzerinde pozitif bir etkisi olmayacağı yönünde çıkarımlara sahiptir (Pollin ve Zhu, 2006, s. 595; Thanh, 2015, s. 42). Dolayısıyla bu görüşler ise enflasyon oranının nötr yani uzun dönemde reel ekonomik aktiviteyi etkilemeyeceği şeklindeki geleneksel klasik anlayışla aynı sonucuna varmaktadır. Teorik modellerde enflasyonun ekonomik büyüme üzerindeki etkileri karmaşıtır ve paranın modellere nasıl dahil edildiğine bağlıdır (López-Villavicencio ve Mignon, 2011, s. 456). Fayda fonksiyonuna parayı dahil ederek Sidrauski (1967) paranın nört olduğu ve diğer bir ifadeyle enflasyonun ekonomik büyüme üzerinde etkisi olmadığını bulmaktadır. Benzer sonuçlar Ireland (1994) tarafından daha güncel modellerde de elde edilmektedir. Ancak diğer taraftan Tobin (1965) paranın sermayenin ikamesi olduğunu varsayarak enflasyonun büyüme üzerindeki etkisini pozitif olarak tespit ederken parayı sermayenin tamamlayıcısı olarak modelleyen Stockman (1981) ise enflasyonun ekonomik büyüme üzerinde negatif etki yarattığı sonucuna varmaktadır.

Makroekonomik istikrar ve fiyat istikrarı para politikasının iki temel amacını oluşturmaktadır. Makroekonomik istikrar büyük oranda sürdürülebilir ekonomik büyümeyi ifade ederken fiyat istikrarı ise düşük enflasyon düzeyini ima etmektedir. Para politikasının bu iki amacının birbiriyle olan ilişkisi her zaman merak konusu olmuştur. Fiyat istikrarı uzun yıllardır makroekonomik istikrar için gerekli bir faktör olarak görülmekte ve para politikası stratejilerinin merkezinde yer almaktadır. $\mathrm{Bu}$ sebeple enflasyonun ekonomik büyüme üzerindeki etkisi hem teorik hem de ampirik literatürde uzun yıllardır tartışılmaktadır. Enflasyon ve ekonomik büyüme ilişkisini inceleyen ilk dönem ampirik çalışmalarda genellikle doğrusal modeller kullanılmaktadır (Barro, 1995, 1996; Levine ve Renelt, 1992; Levine ve Zervos, 1993). Ancak sonraki ilk dönem çalışmalar ise enflasyon ve ekonomik büyüme ilişkisinin doğrusal olmadığını sorgulamaktadır (Fischer, 1993; Sarel, 1996; Ghosh ve Phillips, 1998; Bruno ve Easterly, 1998; Khan ve Senhadji, 2001). Teorik ve ampirik alanda bu tartışma hala devam etmesine rağmen politika yapıcılar tarafından genellikle enflasyonun orta ve uzun dönemde ekonomik büyümeyi negatif etkilediği kabul edilmektedir (Khan ve Senhadji, 2001; Espinoza vd., 2010; López-Villavicencio ve Mignon, 2011). Dolayısıyla makroekonomik istikrar için düşük ve istikrarlı bir enflasyon oranı çoğu merkez bankasının temel hedefi konumundadır. Bu durumda "uygun enflasyon hedefi ne olmalıdır?" sorusu para politikasının yürütülmesinde daha da önem kazanmaktadır. Bu soruya cevap verebilmek için hangi enflasyon düzeyinin üzerinde enflasyonun ekonomik büyümeyi olumsuz yönde etkileyebileceğinin tespit edilmesi gerekmektedir. Özellikle son dönem araştırmalar ise bahsi geçen enflasyon eşik değerinin hangi düzeyde olması gerektiği üzerine yoğunlaşmaktadır. 
Enflasyon ve büyüme ilişkisinde enflasyon eşik değerinin düzeyi ve bu değişkenler arasındaki ilişkinin istatistiksel olarak anlamlılığı örneklem seçimine göre oldukça farkllık göstermektedir. Yapılan çalışmaların çoğu genellikle ülke gruplarını gelişmiş, gelişmekte olan, az gelişmiş ve OECD ülke gruplarına göre ayırmaktadır. Çalışmaların büyük çoğunluğunda en az bir ülke grubu için istatistiksel olarak anlamlı ekonomik büyüme ve enflasyon ilişkisi ve enflasyon eşik değeri tespit edilmesine rağmen OECD ülkelerini inceleyen az sayıdaki çalı̧̧mada ise bu ülke grubu için enflasyon ve ekonomik büyüme arasında istatistiksel olarak anlamlı bir ilişki ve enflasyon eşik değeri tespiti yapılamamıştır (Sepehri ve Moshiri, 2004; Pollin ve Zhu, 2006). Bu çalışmalar enflasyon eşik değer düzeyini genellikle el yordamıyla ya da kukla değişkenler aracılığıyla dışsal bir biçimde belirlemektedir. Diğer çalışmalarda yer alan gelişmiş ülke örneklemlerinin çoğunda bir eşik değer tespit edilebilmesine rağmen çoğunlukla gelişmiş ülkeleri kapsayan OECD ülkelerinde bu değerin tespit edilememesi ilginç görünmekte ve tekrar sorgulanmayı gerektirmektedir. $\mathrm{Bu}$ anlamda bu çalışma eşik değerin içsel olarak belirlenmesine imkân tanıyan Hansen (1999) panel eşik değer modelini kullanarak çoğunlukla ekonomik açıdan gelişmiş, uzun yıllardır nispeten düşük ve istikrarlı enflasyon düzeylerine sahip olan OECD ülkeleri için enflasyon büyüme ilişkisini güncel veri ve ekonometrik yöntemlerle tekrar sorgulamayı amaçlamaktadır. Daha spesifik olarak çalışma doğrusal olmayan enflasyon ve ekonomik büyüme ilişkisine dikkat çekmekte ve belirli bir enflasyon eşik değerinin tespitine odaklanmaktadır. Bu amaç doğrultusunda çalışmada 19962016 yıllarını kapsayan 32 OECD ülkesine ait veriler kullanılmaktadır.

Bu çalışmanın devamı şu şekilde organize edilmektedir: İkinci bölümde doğrusal olmayan enflasyon büyüme ilişkisine odaklanan çalışmaları içeren literatür taramasına yer verilmektedir. Üçüncü bölümde çalışmada kullanılan yöntem ve veri seti tanıtılmaktadır. Dördüncü bölümde ekonometrik model tahminlerine dayanan bulgular değerlendirilmektedir. Beşinci bölümde ise çalışmanın sonuçları tartışılmaktadır.

\section{Literatür Taraması}

Enflasyon ve ekonomik büyüme arasındaki ilişkiyi sorgulayan ampirik çalışmalar teorik çalışmalara paralel bir biçimde ortak bir sonuca varmaktan yoksundur. Bu çalışmaların bulguları kullanılan veri seti ve seçilen yöntemler karşısında oldukça değişkenlik sergilemektedir. Fisher (1993)'a ait çalışma enflasyon ve büyüme arasındaki ilişkinin doğrusal olmayabileceğini sorgulayan ilk çalışmalardan biridir. Gelişmiş ve gelişmekte olan 93 ülkeden oluşan geniş bir panel veri seti kullanan Fisher, ülkeleri enflasyon düzeylerine göre farklı örneklemlere ayırarak farklı enflasyon düzeylerinin ekonomik büyüme üzerinde yarattı̆̆ı etkileri ayrıştırmaya çalışmaktadır. Çalı̧̧mada enflasyon eşik değer düzeyleri dışsal ve enflasyon oranı $\% 15$ 'den küçük, \%15-\%40 arası ve $\% 40$ 'dan büyük olacak şekilde belirlenmiş ve doğrusal olmayan bir enflasyon ve büyüme ilişkisinin varlığına yönelik bulgular elde edilmiştir. Benzer bir şekilde Bruno (1995), 127 ülke için yaptığ çalışmada enflasyon eşik değer seviyesini yaklaşık \%20 dolaylarında tespit etmektedir. Enflasyon \%20-25 bandına kadar büyüme üzerinde pozitif bir etkiye sahipken bu düzeyden sonra enflasyon büyümeyi negatif olarak etkilemektedir. Enflasyon ve ekonomik büyüme ilişkisindeki yapısal kırılmaları 87 ülkeden oluşan bir panel ile test eden Sarel (1996) ise bu düzeyi \% 8 olarak tahmin etmektedir. 
Ancak enflasyonun büyüme üzerindeki etkisini gösteren katsayılar, bu düzeyin üzerinde negatif ve anlamlı iken bu düzeyin altında pozitif fakat anlamsız olarak bulunmaktadır. Ghost ve Phillips (1998)'e ait çalışmada da enflasyon ile büyüme ilişkisinin doğrusal olmadığı tespit edilmektedir. Yazarlara göre çok düşük enflasyon oranlarında iki değişken arasındaki ilişkinin yönü pozitif iken negatif ilişki ancak çok yüksek enflasyon oranlarında ortaya çıkabilmektedir. Diğer çalışmalardan farklı olarak enflasyon krizleri dönemlerine odaklanan Bruno ve Esterly (1998) ise enflasyon ve büyüme arasındaki ilişkiyi 31 ülkenin 1961-1994 dönemine ait veri setini kullanarak araştırmıştır. Çalışmada enflasyon eşik değeri dışsal bir şekilde \%40 olarak belirlenirken yüksek enflasyon krizlerinde büyümenin sert bir biçimde azaldığı ve enflasyon düştükten sonra ise hızlı bir şekilde toparlandığı sonucuna varılmaktadır. Enflasyon ve büyüme ilişkisinin ekonomik ve istatistiksel olarak anlamlı olduğunu gösteren Gylason ve Herbertsson (2001) ise bu çalışmalarında 170 ülkenin 1960-1992 yıllarını kapsayan verilerini kullanmıştır. Ayrıca yıllık enflasyon oranının \%10-20 düzeyini aştığında genellikle uzun dönem büyümeyi olumsuz etkilediği sonucuna da ulaşılmaktadır.

Enflasyon düzeyinin dışsal (arbitrary) olarak seçildiği bu ilk dönem çalışmalardan farklı olarak sonraki çalı̧̧malarda eşik seviyesinin model tarafından belirlenebildiği ekonometrik yöntemler kullanılmaktadır. Hansen (1999)'e ait eşik değer tahmin yöntemini kullanan Khan ve Senhadji (2001), 140 ülkeye ait 1960-1998 yıllarını kapsayan dengesiz panel veri seti ile gelişmiş ve gelişmekte olan ülkeler için farklı enflasyon eşik değer düzeylerini sırasıyla \%1-3 ve \%11-12 olarak tahmin etmektedir. Enflasyon oranları bu seviyenin üzerinde olduğunda enflasyon ve büyüme ilişkisi anlamlı ve negatif iken bu seviyenin altında istatistiksel olarak anlamsız hale gelmektedir. Khan ve Senhadji (2001) çalışmasına benzer bir şekilde gelişmişlik düzeylerine göre ayrılan farklı ülke gruplarını inceleyen Sepehri ve Moshiri (2004)'ye ait olan çalı̧̧mada enflasyon eşik düzeyi; düşük gelirli ülkeler için \%11, düşük-orta gelirli ülkeler için $\% 15$ ve üst-orta gelirli ülkeler için $\% 5$ olarak bulunmaktadır. OECD ülkelerinden oluşan örneklem için elde edilen bulgular ise enflasyon ve ekonomik büyüme ilişkisinin istatistiksel olarak anlamlı olmadığı yönündedir. Bu doğrultuda yapılan bir diğer çalışmada 138 ülkeden oluşan tüm örneklem için enflasyon eşik seviyesi Drukker vd. (2005) tarafından \%19,16 olarak bulunmaktadır. Çalışmada gelir seviyelerine göre sınıflandırılan ülke gruplarını dikkate alan önceki çalışmalardan farklı olarak, endüstrileşmiş ülkeler için \%2,57 ve 12,61 olmak üzere iki ayrı eşik noktası tespit edilmektedir. Finansal gelişme ve ekonomik büyüme ilişkisinde bir enflasyon eşik düzeyinin varlığını araştıran Lee ve Wong (2005)'a ait çalışma bu anlamda diğer çalışmalardan farklılaşmaktadır. Tayvan ve Japonya için yapılan çalışmada enflasyon eşik değeri sırasıyla $\% 7,25$ ve $\% 9,66$ olarak bulunmakta ve enflasyon oranının bu seviyenin altında olduğu durumda finansal gelişmenin ekonomik büyümeyi olumlu yönde etkilediği iddia edilmektedir. İki değişken arasındaki ilişkinin ülke gruplarına göre farklılaştığını ileri süren bir diğer çalışma da Pollin ve Zhu (2006)'ya aittir. 80 ülke verisi ile yaptıkları ampirik tahmin sonuçlarına göre; düşük ve orta gelirli ülkeler için enflasyon büyüme ilişkinin doğrusal olmadığı yönünde kanıtlar elde edilirken bu bulgular yalnızca düşük gelirli ülkeler için istatistiksel olarak anlamlıdır. Her iki ülke grubu için enflasyon seviyesinin kabaca \%15-18 düzeyine kadar büyümeyi ılımlı bir şekilde pozitif etkileyebileceği vurgulanmaktadır. OECD ülkeleri için ise belirgin kanıtlar elde edilememiştir. Li (2006) tarafından 90 gelişmiş ve 27 gelişmekte olan ve ülke için yapılan tahminlerde enflasyon eşik düzeyi gelişmiş ülkeler 
için \%24 ve gelişmekte olan ülkeler için ise $\% 14$ ve $\% 38$ olmak üzere iki farklı eşik değer şeklinde elde edilmektedir. Bu iki seviyenin üzerinde enflasyonun büyüme üzerindeki etkisi, istatistiksel olarak anlamlı olmasına rağmen neredeyse ortadan kalkmaktadır. Vaona ve Schiavo (2007), enflasyon ekonomik büyüme ilişkisini, 1960-1999 dönemi ve 167 ülke verisini kullanarak yarı parametrik ve parametrik olmayan araç değişken tahmincileri ile analiz etmektedir. Çalışmada gelişmiş ülkeler için enflasyonun eşik seviyesi \%12 olarak tahmin edilmesine rağmen bu seviyenin altındaki enflasyon düzeyi önemli bir etkiye sahip değildir. Çalışmada ayrıca gelişmekte olan ülkelerdeki yüksek büyüme oynaklı̆ı̆ndan dolayı bu ülkeler için kesin bir eşik değerin tespit edilemediği vurgulanmaktadır. Bick (2010), gelişmekte olan 40 ülke için yaptığı çalışmasında Hansen (1999) panel eşik modeline rejim sabiti ekleyerek ihmal edilmiş değişkenlerden kaynaklı sapma sorunlarını çözmeye çalışmaktadır. Modele rejim sabitinin eklenmesi eşik değerin \%19'dan \%12'ye düşmesine ve enflasyonun büyüme üzerindeki marjinal etkisini gösteren regresyon katsayılarının yaklaşık iki katına çıkmasına neden olmaktadır.

$\mathrm{Bu}$ alandaki ilk dönem çalışmaların çoğunda eşik düzeyi dışsal olarak belirlenmekte ve gözlemlenemeyen heterojenlik dikkate alınmamaktadır. Son dönem çalı̧̧malarının birçoğu González vd. (2005) tarafından geliştirilen PSTR ${ }^{3}$ (Panel Smooth Transition Regression) modelini kullanmaktadır. Bu model eşik değerin içsel olarak belirlenmesine imkan tanırken, içsellik ve heterojenlik problemlerini çözebilmektedir. Bu modeli kullanan ilk çalı̧malardan biri Omay ve Kan (2010)'a ait olup 6 gelişmiş ülke (Kanada, Fransa, İtalya, Japonya, UK ve $A B D)$ için analiz yapılmıştır. PSTR modeli ile elde edilen sonuçlara göre enflasyon eşik değeri \%2,52 olarak tahmin edilmektedir. Yazarlar ayrıca yatay kesit bağımlılığını kontrol etmek amaciyla SURE-GLS ve CCE (Seemingly Unrelated Regression Equations through Generalized Least Squares ve Common Correlated Effects) yöntemleri ile tahminler yapmaktadır. Bu tahmin yöntemlerine göre enflasyon eşik değeri sırasıyla \%3,18 ve \%2,42 olarak bulunmaktadır. Espinoza vd. (2010) ise 1960-2007 ylllarını kapsayan 165 ülke panel verisini LSTR (Logistic Smooth Transition Regression) modelini kullanarak incelemektedir. Çalışmada tüm ülkeler, gelişmiş ülkeler ve gelişmekte olan ülkeler için enflasyon eşik değeri sırasıyla yaklaşık \%9, \%1 ve \%10 olarak bulunmaktadır. Benzer bir çalışma da LópezVillavicencio ve Mignon (2011) tarafından 1961-2007 dönemini kapsayan 44 ülke verisi kullanılarak yapılmaktadır. PSTR ve GMM yöntemlerine dayanan tahminlerinde yazarlar enflasyon eşik değerini tüm ülkeler için $\% 5$, gelişmiş ülkeler için $\% 1,23$, gelişmekte olan ülkeler için \%14.54, üst-orta gelir grubundaki ülkeler için \%10.27 ve düşük-orta ve düşük gelir grubundaki ülkeler için ise \%19,64 olarak tespit etmektedir. PSTR modelini kullanan Ibarra ve Trupkin (2011)'e ait bir diğer çalışma, enflasyon ve büyüme ilişkisini 120 gelişmiş ve gelişmekte olan ülke için araştırmaktadır. Enflasyonun eşik değeri gelişmiş ülkeler için \%4,1 ve gelişmekte olan ülkeler için \%19,1 olarak tahmin edilmektedir. Yazarlar ayrıca kurumsal kalite düzeylerine göre indirgenen bir grup gelişmekte olan ülke için ise eşik değerin \%7,9’a düştüğünü gözlemlemektedir. Ancak yazarlar diğer çalışmalardan farklı olarak iki örneklemde de enflasyonun büyüme üzerindeki etkisini her iki rejim için negatif olarak bulmaktadır. Enflasyon büyümeyi her iki rejimde de negatif etkilemesine rağmen bu etki yalnızca ikinci 
rejimde yani daha yüksek enflasyon düzeylerinde istatistiksel olarak anlamlıdır. Seleteng vd. (2013) yine aynı model aracilığıyla enflasyon büyüme ilişkisini 1980-2008 dönemi için SADC (South African Development Community) bölgesi özelinde araştırmaktadır. Çalışmada bu bölge için enflasyon eşik değeri \% 18,9 olarak tahmin edilmektedir. Yazarlar, Ibarra ve Trupkin (2011) çalş̧masındaki gibi enflasyonun büyüme üzerindeki etkisini her iki rejimde için negatif olarak bulmaktadır ve bu etki yalnızca yüksek enflasyon rejiminde anlamlıdır.

Diğer taraftan ilgili literatürde Caner ve Hansen (2004) tarafından geliştirilen dinamik panel eşik modeli kullanılarak yapılan tahminlerinde bulunmaktadır. Bu çalışmalardan biri olan Kremer vd. (2013), 120 ülke verisi ile enflasyon büyüme ilişkisinin doğrusal olmadığını tespit etmektedir. Bu model önemli kontrol değişkenlerinin içsellik sorununu çözmeye yardımcı olmaktadır. Yazarlar enflasyon eşik düzeyini endüstrileşmiş ülkeler için \%2,53 ve endüstrileşmemiş ülkeler için \%17,22 olarak bulmaktadır. Enflasyon oranı bu eşik değerlerin üzerinde olduğunda her iki örneklem içinde enflasyon, ekonomik büyümeyi negatif etkilemektedir ve istatistiksel olarak anlamlıdır. Ancak endüstrileşmiş ülkeler için tahmin edilen eşik değerin altında enflasyonun büyüme üzerindeki pozitif etkisi anlamlı değildir. Yöntem bakımından Kremer vd. (2010)'i takip eden bir diğer çalı̧̧a 32 Asya ülkesi için Vinayagathasan (2013) tarafından gerçekleş̧irilmektedir. Çalışmanın sonuçları enflasyon eşik değerinin \%5,43 olduğunu göstermektedir. Enflasyon bu düzeyin üzerinde ekonomik büyümeyi bozucu etki yaratırken enflasyonun etkisi bu düzeyin altında istatistiksel olarak anlamsizdir.

PSTR ve GMM yöntemlerinin her ikisini de kullanan diğer bir çalışmada Eggoh ve Khan (2014), enflasyon büyüme ilişkisini 102 ülke ve 1960-2009 dönemi için incelemektedir. Çalışmanın bulguları enflasyon ekonomik büyüme ilişkisinin doğrusal olmadığını ve enflasyon eşik değerinin tüm örneklem için \%10,5, yüksek gelirli ülkeler için \%3,4, üst-orta gelirli ülkeler için \%10, düşük-orta gelirli ülkeler için \%12,9 ve düşük gelirli ülkeler için \%19,5 olduğunu göstermektedir. Çalışmada ayrıca enflasyon oranının ilgili örneklemler için bu seviyelerin üzerinde olması ekonomik büyümeyi olumsuz etkilerken bu düzeyin altındaki enflasyon oranı ise büyümeye pozitif katkı yaptığı görülmektedir. Benzer bir şekilde Thanh (2015) PSTR ve GMM-IV yöntemleri ile ASEAN-5 ülkeleri özelinde enflasyon büyüme ilişkisini sorgulamaktadır. Çalı̧manın bulguları enflasyon ve ekonomik büyüme ilişkisinin doğrusal olmadığını göstermektedir. Sonuçlara göre enflasyon \%7,84 seviyesinin üzerine çıktığında ekonomik büyümeyi istatistiksel olarak anlamlı bir şekilde negatif etkilemektedir. Gelişmekte olan 92 ülke için esnek bir yarı parametrik panel veri modeli tahmin eden Bağlan ve Yoldaş (2014) enflasyonun \%12 seviyesinden sonra büyümeyi negatif etkilediği ve çok yüksek enflasyon düzeylerinde ise bu ilişkinin anlamsız hale geldiği sonucuna varmaktadır.

Enflasyon ve ekonomik büyüme ilişkisi üzerine yapılan çalışmaların bulguları genel olarak değerlendirildiğinde özellikle son dönem çalışmaların enflasyon ve ekonomik büyüme ilişkisinin doğrusal olmadığı yönünde ortak sonuçlara sahip olduğu söylenebilir. Ancak tahmin edilen enflasyon eşik değerleri incelendiğinde bu değerlerin örneklem seçimi, yöntem ve ekonometrik model tanımlamaları karşısında oldukça hassas olduğu gözlemlenmektedir. 


\section{Yöntem ve Veri Seti}

Çalışmada enflasyonun eşik seviyesini bulmak için Hansen (1999) tarafından geliştirilen statik panel veri modeli kullanılmaktadır. Hansen (1999), $i$ bireysel etkileri, $t$ zamanı temsil ederken dengeli panel veri seti için $\left\{y_{i t}, q_{i t}, x_{i t}: 1 \leq i \leq n, 1 \leq t \leq T\right\}$ bir tahmin önermektedir. Yalnızca bir olası eşik değere sahip olan model:

$$
y_{i t}=\mu_{i}+\beta_{1}^{\prime} x_{i t} I\left(q_{i t} \leq \gamma\right)+\beta_{2}^{\prime} x_{i t} I\left(q_{i t}>\gamma\right)+e_{i t}
$$

olarak ifade edilmektedir. Burada $y_{i t}$ bağımlı değişkeni, $q_{i t}$ eşik değişkenini, $x_{i t}$ dışsal regresörlerin $k$ boyutlu bir vektörü iken; $I($.$) gösterge fonksiyonu e_{i t} \sim\left(0, \sigma^{2}\right)$ ise bağımsız ve özdeş dağılmış (iid) hata terimini temsil etmektedir. Modelde belirtilen $\gamma$ eşik değeridir ve gözlemler $q_{i t}$ 'nin $\gamma$ değerinden büyük veya küçük olmasına bağlı olarak iki "rejime" ayrılmaktadır. $\beta$ değerleri ise farklı iki rejimin eğim parametreleridir. Denklem (1) için yeniden aşağıdaki ifade yazılabilir:

$$
y_{i t}=\begin{aligned}
& \mu_{i}+\beta_{1} x_{i t}+e_{i t}, q_{i t} \leq \gamma \\
& \mu_{i}+\beta_{2} x_{i t}+e_{i t}, \quad q_{i t}>\gamma
\end{aligned}
$$

Ayrıca $x_{i t}(\gamma)=\left(\begin{array}{l}x_{i t} I\left(q_{i t} \leq \gamma\right) \\ x_{i t} I\left(q_{i t}>\gamma\right)\end{array}\right)$ ve $\beta=\left(\beta_{1}^{\prime} \beta_{2}^{\prime}\right)^{\prime}$ olarak ifade edildiğinde denklem (1) farklı bir formda şu şekilde yazılabilir:

$$
y_{i t}=\mu_{i}+\beta^{\prime} x_{i t}(\gamma)+e_{i t}
$$

Hansen (1999), model tahmini için ilk olarak bireysel etkileri $\left(\mu_{i}\right)$ yok etmenin yolunun bireye özgü spesifik etkilerin ortadan kaldırılması olduğunu öngörmektedir. Bunun için denklem (1)'in zaman indeksi $t$ üzerinden ortalaması alındığında:

$$
\bar{y}_{i}=\mu_{i}+\beta^{\prime} \bar{x}_{i}(\gamma)+\bar{e}_{i}
$$

şeklinde ifade edilebilir. Bu eşitlikte $\bar{y}_{i}=T^{-1} \sum_{t=1}^{T} y_{i t}$ ve $\bar{e}_{i}=T^{-1} \sum_{t=1}^{T} e_{i t}$ iken $\bar{x}_{i}(\gamma)=$ $T^{-1} \sum_{t=1}^{T} x_{i t}(\gamma)=\left(\begin{array}{c}T^{-1} \sum_{t=1}^{T} x_{i t} I\left(q_{i t} \leq \gamma\right) \\ T^{-1} \sum_{t=1}^{T} x_{i t} I\left(q_{i t}>\gamma\right)\end{array}\right)$ şeklindedir. Denklem (3) ve (4)'ün farkı alınarak elde edilen denklem ise aşağıdaki şekilde yeniden yazılabilir:

$$
y_{i t}^{*}=\beta^{\prime} x_{i t}^{*}(\gamma)+e_{i t}^{*}
$$

Yukarıdaki eşitlikte $y_{i t}^{*}=y_{i t}-\bar{y}_{i}, \quad x_{i t}^{*}(\gamma)=x_{i t}(\gamma)-\bar{x}_{i}(\gamma)$ ve $e_{i t}^{*}=e_{i t}-e_{i t}{ }^{\prime}$ yi temsil etmektedir. Veriler bir $\gamma$ için $\beta$ eğim katsayısı en küçük kareler yöntemi ile tahmin edilebilir:

$$
\hat{\beta}(\gamma)=\left(X^{*}(\gamma)^{\prime} X^{*}(\gamma)\right)^{-1} X^{*}(\gamma)^{\prime} Y^{*}
$$

Elde edilen tahminde hata terimleri kareleri toplamı olan $S_{1}(\gamma)=\hat{e}^{*}(\gamma)^{\prime} \hat{e}^{*}(\gamma)=Y^{*^{\prime}}(I-$ $\left.X^{*}(\gamma)^{\prime}\left(X^{*}(\gamma)^{\prime} X^{*}(\gamma)\right)^{-1} X^{*}(\gamma)^{\prime}\right) Y^{*}$ eşitlik yardımıyla $\gamma$ eşik değerinin en küçük kareler tahmincisi ise şu şekilde ifade edilmektedir:

$$
\hat{\gamma}=\arg \min _{\gamma} S_{1}(\gamma)
$$

$\hat{\gamma}$ bulunduğunda eğim katsayısı tahmini $\hat{\beta}=\hat{\beta}(\hat{\gamma})$ olarak elde edilir. Hansen (1999) son olarak artık terim varyans tahmini ise aşağıdaki şekilde bulmaktadır: 


$$
\hat{\sigma}^{2}=\frac{1}{n(T-1)} \hat{e}^{*^{\prime}} \hat{e}^{*}=\frac{1}{n(T-1)} S_{1}(\hat{\gamma})
$$

Kullanılan bu yöntemde eşik değerin anlamlılı̆̆ını test etmek için kurulan $H_{0}: \beta_{1}=$ $\beta_{2}$ şeklindeki sıfır hipotezi eşik etkisinin olmadığını göstermektedir. Diğer yandan model (1) yalnızca bir eşik değere sahiptir; fakat bu çalışmada olduğu gibi bazı durumlarda iki veya daha çok eşik değerli model test edilmesi gerekebilir. Örneğin; iki eşik değerli model şu şekilde yazılabilir:

$$
y_{i t}=\mu_{i}+\beta_{1}^{\prime} x_{i t} I\left(q_{i t} \leq \gamma_{1}\right)+\beta_{2}^{\prime} x_{i t} I\left(\gamma_{1}<q_{i t} \leq \gamma_{2}\right)+\beta_{3}^{\prime} x_{i t} I\left(\gamma_{2}<q_{i t}\right)+e_{i t}
$$

Burada eşik değerler $\gamma_{1}<\gamma_{2}$ olmaktadır. Hansen (1999) iki eşik değerli modelden yola çıkarak daha yüksek dereceli eşik değer modellerinin de kolay bir şekilde türetilebileceğini göstermektedir. Bu nedenle Hansen (1999)'in çalışmasında ilk olarak model (9) için tahmin yapılmakta, daha sonra çift eşiğin varlığı tespit edilmekte ve son olarak da $\gamma_{1}, \gamma_{2}$ eşik değer parametreleri için güven aralıkları oluşturulmaktadır. Çoklu eşik modeli değerlendirildiğinde hipotezler: $H_{0}: \beta_{1}=\beta_{2}, H_{1}: \beta_{1} \neq \beta_{2}$ şeklinde iken sıfır hipotezinin reddi en az bir eşik değerinin var olduğunu göstermektedir.

Bu çalışmada ise enflasyon ve ekonomik büyüme ilişkisini sorgulamada kullanılan ampirik modelin formu aşağıdaki gibidir:

$$
\begin{gathered}
y_{i t}=u_{i}+\beta_{1} \tilde{\pi}_{i t} I\left(\tilde{\pi}_{i t} \leq \gamma_{1}\right)+\beta_{2} \tilde{\pi}_{i t} I\left(\gamma_{1}<\tilde{\pi}_{i t} \leq \gamma_{2}\right)+\beta_{3} \tilde{\pi}_{i t} I\left(\gamma_{2}<\tilde{\pi}_{i t} \leq \gamma_{3}\right)+ \\
\beta_{4} \tilde{\pi}_{i t} I\left(\gamma_{3}<\tilde{\pi}_{i t}\right)+\delta X_{i t}+\varepsilon_{i t}
\end{gathered}
$$

Bu model üçlü eşik modelidir. $y_{i t}$, bağımlı değişken ve $i$ ülkesinin $t$ dönemindeki kişi başına GSYH büyüme oranını $\varepsilon_{i t}$ ise hata terimini ifade etmektedir. $u_{i}$ ülkeye özgü sabit etkileri göstermektedir. $\tilde{\pi}_{i t}$ dişsal eşik değişkeni olan enflasyon oranı ve $I$ gösterge fonksiyonudur. $\gamma_{1}$, $\gamma_{2}$ ve $\gamma_{3}$ çoklu eşik modelinde enflasyon için eşik parametrelerini temsil etmektedir. Son olarak $X_{i t}$ kontrol değişkenlerinden oluşan vektördür.

Çalışmada kullanılan tüm değişkenlere ait bilgiler ve betimleyici istatistikler Tablo 1'de yer almaktadır. Bu bilgilere göre OECD ülkelerinde ilgili dönemde ortalama enflasyon oranı \%2,72 görülen en yüksek enflasyon oranı değeri ise \%2,87 civarındadır. Bu oranlar dikkate alındığında OECD ülkelerinin nispeten düşük ve istikrarlı enflasyon oranlarını sahip olduğu söylenebilmektedir. Tablo 2 ise değişkenlere ait korelasyon katsayılarını göstermektedir. Enflasyon ve kişi başına GSYH arasındaki korelasyon katsayısı anlamlı fakat beklenmedik bir şekilde pozitiftir. Başlangıç geliri ve nüfus büyüme oranı değişkenleri ise beklenildiği gibi kişi başına GSYH ile negatif korelasyona sahip ve anlamlıdır. Yatırımlar ve ticari açıklık değişkenleri ise beklendiği gibi pozitif korelasyona sahip olmasına rağmen bu korelasyonlar son derece düşük ve istatistiksel olarak anlamsızdır. 
Tablo 1. Değişkenler, Tanımları, Kaynakları ve Betimleyici ístatistikler

\begin{tabular}{|c|c|c|c|c|c|c|}
\hline Değişkenler & Tanımı ve Kaynağı & $\begin{array}{l}\text { Göz. } \\
\text { Say. }\end{array}$ & Ort. & $\begin{array}{c}\text { Std. } \\
\text { Sapma }\end{array}$ & Min. & Maks. \\
\hline $\begin{array}{l}\text { Kişi Başına GSYH } \\
\text { Büyüme Oranı }(y)\end{array}$ & $\begin{array}{l}2010 \text { sabit fiyatlarıyla } A B D \text { doları } \\
\text { cinsinden GSYH'nin yıl ortası nüfusa } \\
\text { bölümünün \% değişimi, OECD Data }\end{array}$ & 320 & 0,020 & 0,028 & $-0,105$ & 0,148 \\
\hline $\begin{array}{l}\text { Başlangıç Geliri } \\
\text { (linpercap) }\end{array}$ & $\begin{array}{l}2010 \text { sabit fiyatlarıyla ABD doları } \\
\text { cinsinden GSYH'nin bir önceki döneminin } \\
\text { logaritması, OECD Data }\end{array}$ & 320 & 10,354 & 0,627 & 8,625 & 11,593 \\
\hline $\begin{array}{l}\text { Enflasyon Oranı } \\
(\pi)\end{array}$ & Tüketici fiyatları endeksindeki \% değişim & 320 & 2,725 & 2,641 & $-1,524$ & 20,871 \\
\hline $\begin{array}{l}\text { Nüfus Büyüme } \\
\text { Oranı (popg) }\end{array}$ & Yıllık nüfus büyüme oranı, OECD Data & 320 & 0,515 & 0,697 & $-1,951$ & 2,793 \\
\hline Yatırım (inv) & $\begin{array}{l}\text { Finansal olmayan net yatırımların GSYH'ye } \\
\text { oranı, OECD Data }\end{array}$ & 320 & 1,595 & 0,959 & $-0,578$ & 5,400 \\
\hline $\begin{array}{l}\text { Ticari Açıklık } \\
\text { (topen) }\end{array}$ & $\begin{array}{l}2010 \text { sabit fiyatlarıyla ABD doları } \\
\text { cinsinden mal ve hizmet ihracat ve ithalat } \\
\text { toplamının GSYH'ye oranı, OECD Data }\end{array}$ & 320 & 0,893 & 0,529 & 0,201 & 3,751 \\
\hline
\end{tabular}

Tablo 2. Değişkenlere Ait Korelasyon Matrisi

\begin{tabular}{|c|c|c|c|c|c|c|}
\hline & $y$ & infl & linpercap & popg & inv & topen \\
\hline$y$ & 1.0000 & & & & & \\
\hline infl & $0.1917 * * *$ & 1.0000 & & & & \\
\hline linpercap & $-0.3272 * * *$ & $-0.5149 * * *$ & 1.0000 & & & \\
\hline popg & $-0.1591 * * *$ & $-0.1534 * * *$ & $-0.5146 * * *$ & 1.0000 & & \\
\hline inv & 0.0595 & $0.1119 * *$ & $-0.1752 * * *$ & $-0.1705 * * *$ & 1.0000 & \\
\hline topen & 0.0753 & -0.0378 & $0.1543 * * *$ & $0.1202 * *$ & 0.0844 & 1.0000 \\
\hline
\end{tabular}




\section{Ampirik Bulgular}

Enflasyon büyüme ilişkisinde enflasyonun eşik değer sayısını belirleyebilmek için (10) numaralı model üç eşik düzeyi içerecek şekilde en küçük kareler yöntemi kullanılarak tahmin edilmektedir. Çoklu eşik modeline ait bulgular Tablo 3'de gösterilmektedir. $\hat{\gamma}_{1}, \hat{\gamma}_{2}$ ve $\hat{\gamma}_{3}$ sırasıyla modelde tahmin edilen birinci, ikinci ve üçüncü eşik değerlerini göstermektedir. $\mathrm{Bu}$ değerler modelde sırasıyla 3,62, 3,50 ve 5,14 olmak üzere üç farklı eşik değerin tespit edildiğini ifade etmektedir.

Tablo 3'de ayrıca tahmin edilen eşik parametrelerinin F-istatistikleri ve bu istatistiklere ait boostraplı p-değerleri bulunmaktadır. Birinci eşik parametresinin F-istatistiği \%5 ve \%10 kritik değerlerinden büyük fakat \%1 kritik değerinden küçüktür. Diğer testlerdeki her iki parametre için ise F-istatistikleri her üç kritik değerden de küçüktür. Dolayısıyla elde edilen bulgular tahmin edilen modelde tek eşik değeri olduğunu desteklemektedir. İki ve üçüncü eşik değerlerinin F-istatistikleri anlamlı görünmemektedir.

Eşik parametrelerinin nokta tahminlerine ait güven aralıkları bilgileri Şekil 1, Şekil 2 ve Şekil 3'de sırasılyla birinci, ikinci ve üçüncü eşik parametresi için gösterilmektedir. LR istatistiğinin sıfıra değdiği noktalar tahmin edilen eşik değerini göstermektedir. LR istatistiğinin eşik parametresi değerinde kırmızı kesikli çizginin altında yer alması parametrenin \%95 güven aralığında anlamlı olduğunu ifade etmektedir. Bu bilgilere göre yalnızca Şekil 1'de yer alan birinci eşik parametresi istatistiksel olarak \%95 güven aralığında anlamlıdır. Diğer eşik parametrelerine ilişkin bulgular anlamlı değerler sergilememektedir. Tablo 3'de yer alan sonuçlar LR istatistiğinden elde edilen bulgular ile desteklenmektedir. Dolayısıyla regresyon modelinde bu aşamadan sonra bir adet eşik düzeyi olduğu kabul edilerek tek eşikli regresyon modeli tahmin edilmektedir.

Tablo 3. Eşik Değer Testi

\section{Bir Eşik Değer için Test}

$\begin{array}{ll}\hat{\gamma}_{1} & 3,6207\end{array}$

F-istatistiği $\quad 8,63$
p-degeri

p-değeri $\quad 0,040$

(\%10, \%5 ve \%1 kritik değerleri)

$(7,2001),(7,7433),(9,4623)$

îki Eşik Değer için Test

$\begin{array}{lc}\hat{\gamma}_{2} & 3,5086 \\ \text { F-istatistiği } & 3,72 \\ p \text {-değeri } & 0,7400\end{array}$

(\%10, \%5 ve \%1 kritik değerleri)

(11,1546), (15,0799), (19,3744)

Üç Eşik Değer için Test

\begin{tabular}{lc}
\hline$\hat{\gamma}_{3}$ & 5,1404 \\
\hline F-istatistiği & 3,16 \\
$p$-değeri & 0,8200 \\
$(\% 10, \% 5$ ve \%1 kritik değerleri) & $(10,3342),(13,1916),(14,5583)$ \\
\hline
\end{tabular}

Not: Her üç eşik modelde $p$-değerleri için 1000 bootstrap simülasyonu kullanılmıştır. 
Enflasyon ve ekonomik büyüme arasındaki ilişkiye ait panel eşik regresyon modeline ait tahminler Tablo 4'de yer almaktadır. Daha önce belirtildiği üzere Tablo 4'deki sonuçlar tekli eşik modeli tahminlerinden elde edilmektedir. Tablo 3'de ilk olarak daha önce tahmin edildiği gibi enflasyonun eşik düzeyine ilişkin nokta tahmin yer almaktadır. $\hat{\gamma}_{1}$ eşik parametresi 3,6207 olarak tahmin edilmektedir ve \%5 anlamlılık düzeyinde istatistiksel olarak anlamlıdır. Dolayısıyla tahminler enflasyon oranını bu düzeyi aştıktan sonra bir rejim değişikliği gerçekleştiğini ifade etmektedir.

Tablo 4 ayrıca enflasyon eşik değerine bağlı olarak enflasyonun büyüme üzerindeki etkilerini göstermektedir. $\hat{\beta}_{1}$ ve $\hat{\beta}_{2}$ enflasyonun büyüme üzerindeki rejime bağlı etkisini gösteren katsayılardır. Rejim değişkeninin katsayılarına ait istatistikler enflasyon ve büyüme arasındaki ilişkinin ilgili örneklem için doğrusal olmadığını göstermektedir. $\hat{\beta}_{1}$ katsayısı pozitif fakat istatistiksel olarak anlamsızdır. $\hat{\beta}_{2}$ ise negatif ve istatistiksel olarak $\% 5$ düzeyinde anlamlıdır. $\mathrm{Bu}$ bulgulara göre enflasyon oranı 3,6207 düzeyinin altında iken enflasyon ekonomik büyümeyi pozitif etkilerken enflasyon oranı bu eşik değerin üzerine çıktığında enflasyon ekonomik büyüme üzerinde bozucu bir etki yaratmaktadır. Enflasyon büyüme ilişkisinin doğrusal olmamasının yanı sıra pozitif ve negatif etkilerin büyüklüğü de farklılaşmaktadır. Marjinal etkileri gösteren katsayıların büyüklüğüne baktığımızda enflasyonun büyüme üzerindeki negatif etkisinin, pozitif etkisine göre yaklaşık iki kat fazla olduğu görülmektedir.

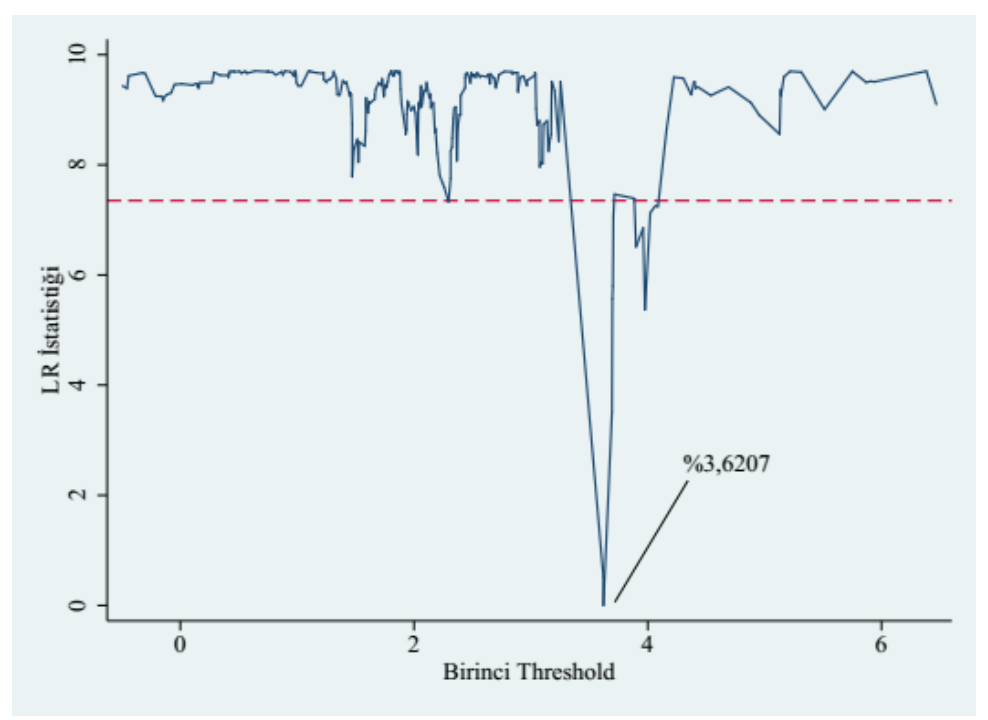

Şekil 1. Üçlü Eşik Modeli Iç̧in Birinci Eşik Değerin Güven Aralıkları: LR istatistiği 


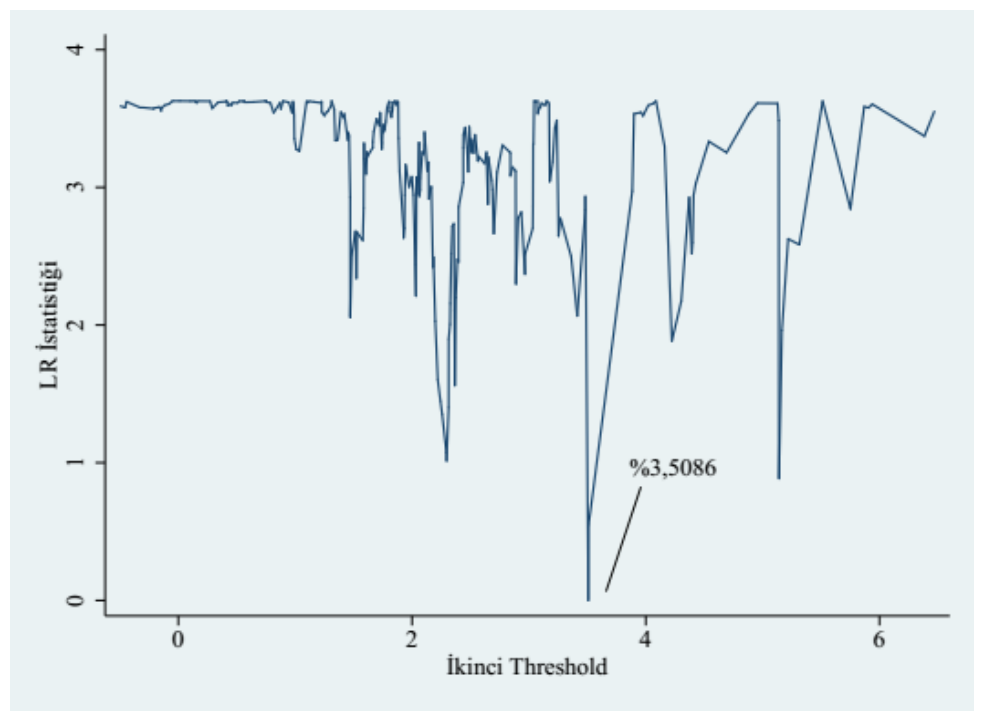

Şekil 2. Üçlü Eşik Modeli Iç̧in ikinci Eşik Değerin Güven Aralıkları: LR ístatistiği

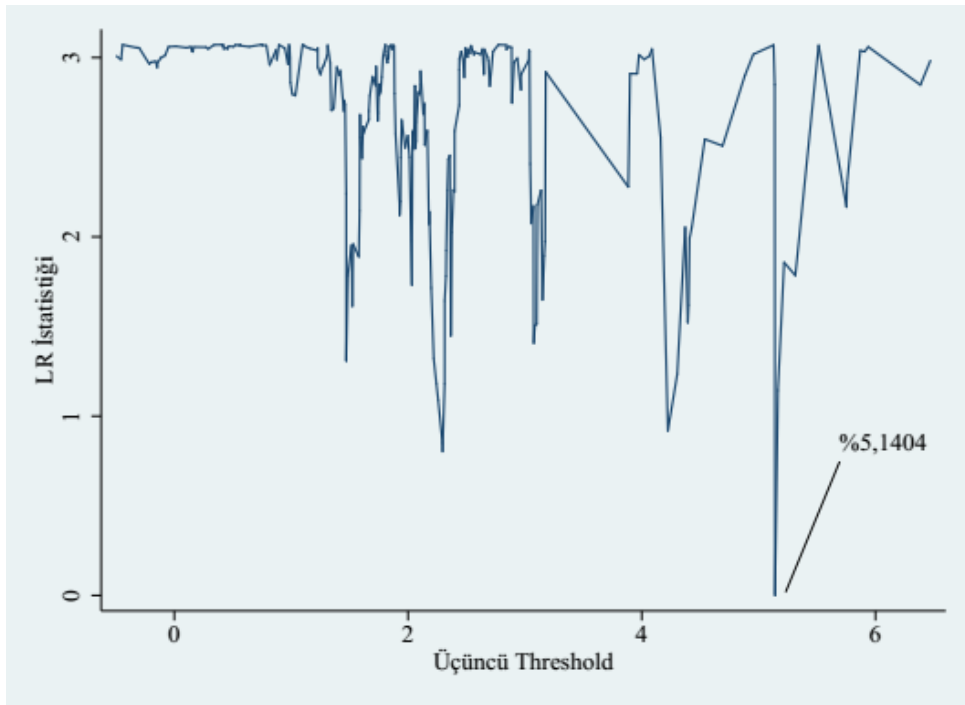

Şekil 3. Üçlü Eşik Modeli iç̧in Üçüncü Eşik Değerin Güven Aralıkları: LR İstatistiği

Çalışmamızda OECD ülkeleri için tahmin edilen eşik değeri ve enflasyon ve ekonomik büyüme ilişkisinin yönüne ilişkin bulgular, OECD ülkelerini inceleyen önceki çalışmalardan oldukça farklıdır. 24 OECD ülkesi ile tahminler yapan Sepehri ve Moshiri (2004) anlamlı ya da anlamsız bir yapısal kırılma yani eşik değeri tespit edememektedir. Pollin ve Zhu (2006) ise enflasyon büyüme ilişkisinin doğrusal olmadığı yönünde kanıtlar tespit etmesine rağmen bu kanıtlar istatistiksel olarak anlam taşımamaktadır. Yazarlar ayrıca farklı tahmincilere dayandırdıkları enflasyon eşik değerlerini sırasıyla $1,8,-3,4$ ve 65 olarak oldukça farklı değerlerde tahmin etmektedirler.

Son olarak modelde ampirik büyüme literatüründe sıklıkla kullanılan değişkenlerin etkileri kontrol edilmektedir. Nüfus büyüme oranı dışındaki değişkenlerin tümü istatistiksel olarak anlamdır. Nüfus büyüme oranındaki artışların kişi başı GSYH büyüme oranı üzerindeki etkisinin negatif olduğu görülmektedir. Diğer yandan başlangıç gelir düzeyi katsayı \%1 anlamlılık düzeyine sahip, oldukça yüksek ve negatif işarete sahiptir. Vinayagathasan (2013) 
ve Seleteng vd. (2013)'nin çalışmalarında vurguladığı gibi bu sonuç zengin ülkelerin yavaş ve fakir ülkelerin hızlı büyüdüğünü göstermesi bakımından koşullu yakınsama hipotezi ile tutarlıdır. Son olarak yatırım ve dışa açıklık oranının katsayıları beklenildiği gibi pozitif ve \%1 ve \%5 düzeyinde istatistiksel olarak anlamlıdır. Yatırımların GSYH'ye oranı ve ithalat ve ihracatın GSYH'ye oranındaki artışların her ikisinin de beklenildiği gibi kişi başına GSYH'yi artırıcı yönde etki ettiği görülmektedir.

Tablo 4. Panel Regresyon Tahminleri: Tekli Eşik Modeli

\begin{tabular}{lc}
\hline Bağımlı Değişken: Kişi Başına GSYH Büyüme Oranı $(y)$ & 3,6207 \\
\hline Eşik Değer Parametresi $\left(\hat{\gamma}_{1}\right)$ & $(0,040)$ \\
Eşik Değer Parametre Anlamlılığı Için p-değeri & 0,134 \\
\hline$\hat{\beta}_{1}$ & $(0,76)$ \\
$\hat{\beta}_{2}$ & $-0,254^{* *}$ \\
& $(-2,44)$ \\
\hline linpercap & $-13,121^{* * *}$ \\
popg & $(-8,63)$ \\
& $-0,370$ \\
inv & $(-0,78)$ \\
topen & $1,050^{* * *}$
\end{tabular}

Not: Parantez içindeki değerler katsayılara ait t-istatistik değerleridir. ${ }^{* * *},{ }^{* *}$ ve ${ }^{*}$ simgeleri sırasıyla değişkenlere ait katsayıların $\% 1, \% 5$ ve \%10 düzeyinde istatistiksel olarak anlamlı olduğunu göstermektedir.

\section{Sonuç}

Bu çalışma Hansen (1999) panel eşik değer modelini kullanarak 32 OECD ülkesine ait 19962016 yılları arasını kapsayan veriler ile enflasyon ve ekonomik büyüme ilişkisini sorgulamaktadır. Bu yöntem OECD ülkelerini inceleyen ilk dönem çalışmalardan farklı olarak eşik değerin içsel olarak belirlenmesine ve ayrıca ampirik modelde kaç tane eşik değer olduğunun tespitine imkan tanımaktadır. Çoklu eşik değer testlerinin yapıldığı analizlerde enflasyon büyüme ilişkisinde yalnız bir adet anlamlı enflasyon eşik değeri olduğu tespit edilmektedir. Bu değer OECD ülkeleri için \%3,6207 olarak tahmin edilmektedir. Tahmin edilen enflasyon eşik değeri ilgili örneklemin \%2,725 olan enflasyon ortalamasının yaklaşık \%33 üzerinde yer almaktadır. Bu eşik değere ilişkin elde edilen bulgular enflasyonun büyüme üzerindeki etkisinin doğrusal olmadığı yönünde güçlü kanıtlar sunmaktadır. Enflasyon oranı \%3,6207'nin altında iken enflasyon ekonomik büyümeyi pozitif etkilemesine rağmen bu etki istatistiksel olarak anlamsızdır. Ancak enflasyon oranı \%3,6207’nin üzerinde 
iken enflasyon ekonomik büyümeyi negatif etkilemekte ve enflasyonun büyüme üzerindeki etkisinin şiddeti de artmaktadır. Bu çalışma, sonuçları itibariyle enflasyon ve ekonomik büyüme ilişkisinde ilgili örneklem için bir eşik değer tespiti ve doğrusal olmayan bir ilişkinin belirlenemediği Sepehri ve Moshiri (2004) ile Pollin ve Zhu (2006) çalışmalarının sonuçlarından farklılaşmaktadır. Ayrıca ekonomik büyüme üzerindeki etkisini kontrol ettiğimiz yatırım ve dışa açıklık değişkenlerinin etkileri pozitif iken başlangıç gelir düzeyine ilişkin bulgularımız ise koşullu yakınsama hipotezini desteklemektedir.

Enflasyon ve ekonomik büyüme ilişkisine dair sunduğumuz bu kanıtlar para politikasının tasarımı, yürütülmesi ve enflasyon hedeflemesi rejimi ile doğrudan ilişkilidir. Enflasyonun ekonomik büyüme üzerindeki doğrusal olmayan etkisinden dolayı para politikası da enflasyon düzeyine bağlı olarak ekonomik büyüme üzerinde farklı etkilere sahip olabilir. Fiyat istikrarının tek başına makroekonomik istikrarı sağlamadaki rolü konusundaki inanış her ne kadar 2008 küresel finansal krizi sonrasında sarsılmış olsa da fiyat istikrarı hala makroekonomik istikrarın en temel belirleyicisi konumundadır. Dolayısıla para politikası tasarımında fiyat istikrarı amacı hala önemini korumaktadır. Çalışmanın sonuçlarının özellikle enflasyon hedeflemesi rejimi uygulayan ülkeler başta olmak üzere para politikası otoritelerine yol gösterici olması beklenmektedir. Merkez bankaları enflasyon oranını tahmin edilen eşik değere düşürerek ekonomik büyümenin artmasına katkıda bulunabilir.

$\mathrm{Bu}$ çalışma birkaç açıdan geliştirilebilir. Öncelikle model belirleme hatalarını en aza indirebilmek amacıyla ampirik büyüme literatüründen hareketle büyüme üzerinde etkili olduğu düşünülen diğer değişkenlerin etkisi kontrol edilebilir. Bunun yanı sıra çalışmada kullanılan model içsellik problemini çözememektedir. OECD ülkeleri özelinde yapılacak sonraki çalışmalar González vd. (2005) tarafindan geliştirilen ve içsellik problemini dikkate alan PSTR modelini kullanabilir. Bu model ayrıca dengesiz panel veri ile çalışabilmeye olanak verdiği için örneklem ve değişken kısıtını büyük oranda ortadan kaldırabilir.

\section{Kaynakça}

Baglan, D., Yoldas, E. (2014). Non-Linearity in The Inflation-Growth Relationship In Developing Economies: Evidence From A Semiparametric Panel Model.Economics Letters, 125(1), 93-96.

Barro, R. J. (1995). Inflation and Economic Growth. Bank of England Quarterly Bulletin, 35(2), 407-443.

Barro, R. J. (1996). Inflation and Economic Growth. Federal Reserve of St. Louis Review, 78, 153-169.

Bick, A. (2010). Threshold Effects of Inflation on Economic Growth In Developing Countries. Economics Letters, 108(2), 126-129.

Bruno, M. (1995). Does Inflation Really Lower Growth?. Finance and Development, 32(3), 3538. 
Bruno, M., Easterly, W. (1998). Inflation Crises and Long-Run Growth. Journal of Monetary Economics, 41(1), 3-26.

Caner, M., Hansen, B.E. (2004). Instrumental Variable Estimation of a Threshold Model. Econometric Theory, 20(5), 813-843.

David, D., Pedro, G., Paula, H. (2005). Threshold Effects in the Relationship Between Inflation and Growth: A New Panel-data Approach. Germany: University Library of Munich. https://mpra.ub.uni-muenchen.de/38225/.

Eggoh, J.C., Khan, M. (2014). On the Non-Linear Relationship Between Inflation and Economic Growth. Research in Economics, 68, 133-143.

Espinoza, R.A., Prasad, A., Leon, Mr Hl. (2010). Estimating the Inflation-Growth Nexus: A Smooth Transition Model. International Monetary Fund, 10-76.

Fischer, S. (1993). The Role of Macroeconomic Factors in Growth. Journal of Monetary Economics, 32(2), 485-512.

Ghosh, A., Phillips, S. (1998). Warning: Inflation May Be Harmful to Your Growth. IMF Staff Papers, 45(4), 672-710.

González, A., Teräsvirta, T., Van Dijk, D. (2005). Panel Smooth Transition Regression Models. SSE/EFI Working Paper Series in Economics and Finance, 604.

Gylfason, T., Herbertsson, T. (2001). Does Inflation Matter for Growth. Japan and the World Economy, 13(4), 405-428.

Hansen, B. E. (1999). Threshold Effects in Non-Dynamic Panels: Estimating, Testing and Inference. Journal of Econometrics, 93, 345-368.

Hansen, B. E. (2000). Sample Splitting and Threshold Estimation. Econometrica, 68(3), 575603.

Ibarra, R., Danilo T. (2011). The Relationship between Inflation and Growth: A Panel Smooth Transition Regression Approach For Developed and Developing Countries. Banco Central del Uruguay Working Paper Series, 6.

Khan, M. S., Ssnhadji, A. S. (2001). Threshold Effects in The Relationship Between Inflation and Growth. IMF Staff papers, 48(1), 1-21.

Kremer, S., Bick, A., Nautz, D. (2013). Inflation and Growth: New Evidence from a Dynamic Panel Threshold Analysis. Empirical Economics, 44(2), 861-878.

Lee, C., Wong, S. Y. (2005). Inflationary Threshold Effects in The Relationship Between Financial Development and Economic Growth: Evidence From Taiwan And Japan. Journal of Economic Development, 30(1), 49.

Levine, R., Renelt, D. (1992). A Sensitivity Analysis of Cross-Country Growth Regressions. American Economic Review, 82(4), 942-963.

Levine, R., Zervos, S. J. (1993). What We Have Learned About Policy and Growth From Crosscountry Regressions. American Economic Review, 83(2), 426-430. 
Li, M. (2006). Inflation and Economic Growth: Threshold Effects and Transmission Mechanisms. Department of Economics, University of Alberta, 2(5), 8-14.

López-Villavicencio, A., Mignon, V. (2011). On the impact of inflation on output growth: Does the level of inflation matter?. Journal of Macroeconomics, 33(3), 455-464.

Omay, T., Kan, E. Ö. (2010). Re-examining the threshold effects in the inflation-growth nexus with cross-sectionally dependent non-linear panel: Evidence from six industrialized economies. Economic Modelling, 27(5), 996-1005.

Pollin, R., Zhu, A. (2006). Inflation and Economic Growth: A Cross-Country Nonlinear Analysis. Journal of post Keynesian economics, 28(4), 593-614.

Sarel, M. (1996). Non-Linear Effects of Inflation on Economic Growth. IMF Staff Papers, 43(1), 199-215.

Seleteng, M., Bittencourt, M., Van Eyden, R. (2013). Non-Linearities in Inflation Growth Nexus in The SADC Region: A Panel Smooth Transition Regression Approach. Economic Modelling, 30, 149-156.

Sepehri, A., Moshiri, S. (2004). Inflation-Growth Profiles Across Countries: Evidence from Developing and Developed Countries. International Review of Applied Economics, 18(2), 191-207.

Thanh, S. D. (2015). Threshold Effects of Inflation on Growth in The ASEAN-5 Countries: A Panel Smooth Transition Regression Approach. Journal of Economics, Finance and Administrative Science, 20(38), 41-48.

Vaona, A., Schiavo, S. (2007). Nonparametric and Semiparametric Evidence on The LongRun Effects of Inflation on Growth. Economics Letters, 94(3), 452-458.

Vinayagathasan, T. (2013). Inflation and Economic Growth: A Dynamic Panel Threshold Analysis For Asian Economies. Journal of Asian Economics, 26, 31-41. 